\title{
BLOOD PRESSURE CHANGES IN POSTMENOPAUSAL WOMEN
}

\author{
Madhavi Dattatrya Rao Kulkarni', ShaktiprasadHiremath ${ }^{2}$
}

${ }_{1}^{1}$ Assistant Professor, Department of Physiology, KIMS, Hubli, Karnataka, India.

${ }^{2}$ Assistant Professor, Department of Physiology, KIMS, Hubli, Karnataka, India.

\section{BACKGROUND}

ABSTRACT

Women are prone to become hypertensive after menopause. Women of different ethnicity show higher prevalence of coronary artery disease and hypertension after menopause. Due to ovarian hormone deficiency, women after menopause can suffer from metabolic syndrome and hypertension compared with those in premenopausal period. After menopause changes like weight gain, tolerance to insulin, sympathetic tone, lipid changes, salt sensitivity occur in our body and these interact with one another, highlighting ovarian hormone deficiency and ageing. We wanted to compare the blood pressure differences in premenopausal with postmenopausal women.

\section{METHODS}

This is a comparative cross-sectional study. Healthy fifty post-menopausal women aged 50 to 55 yrs. and fifty premenopausal healthy women aged 35-40 yrs. with height and weight matched were included in the study. Data was obtained via comprehensive questionnaire. Statistical analysis was done by using student ' $\mathrm{t}$ ' test.

\section{RESULTS}

Statistically significant higher systolic and diastolic blood pressure was observed in postmenopausal women. Also, resting pulse rate was slightly higher in postmenopausal women.

\section{CONCLUSIONS}

Oestrogen deficiency leads to oxidative stress due to release of free radical or reactive oxygen species (ROS) which causes various pathologies like hypertension. In postmenopausal women, oxidative stress causes potential oxidative injury in the cells developing potential oxidative injury in the cells causing disease in this stage of life. ${ }^{2}$ Natural menopause does not immediately aggravate heart disease which may be due to both age and oestrogen deficiency.

HOW TO CITE THIS ARTICLE: Kulkarni MDR, Hiremath S. Blood pressure changes in postmenopausal women. J. Evolution Med. Dent. Sci. 2019;8(15):1248-1250, DOI: 10.14260/jemds/2019/277

\section{BACKGROUND}

Menopause is a natural event with loss of cyclic ovarian functions. Lipid profile changes leading to heart disease may be due to oestrogen deficiency. Vascular tone changes occur due to raise in nitric oxide production which in turn is under oestrogen influence. This further increases the antioxidant effects. Endothelial cells are stabilized, altering fibrinolytic protein. Cardioprotective mechanisms are lost in menopause. ${ }^{3}$

Differences in blood pressure can increase the risk of coronary artery disease in women after menopause in western countries because of their life style, stress, smoking, and food habits.

\section{Aim of The Study \\ We wanted to study the blood pressure differences between post-menopausal women aged 50 to 55 years and height and weight matched premenopausal healthy women aged 35-40 yrs.}

\section{Blood Pressure Differences}

- $\quad$ Systolic blood pressure.

- $\quad$ Diastolic blood pressure.

'Financial or Other Competing Interest': None.

Submission 22-02-2019, Peer Review 27-03-2019,

Acceptance 04-04-2019, Published 15-04-2019.

Corresponding Author:

Dr. Madhavi Dattatrya Rao Kulkarni,

Department of Physiology,

KIMS, Hubli, Karnataka, India.

E-mail:madhavidesai20007@gmail.com

DOI: $10.14260 / j e m d s / 2019 / 277$

\section{METHODS}

It was done in the department of Physiology, KIMS Hubli. Ethical approval was obtained from the ethical committee of KIMS Hubli.

\section{Source of Data}

Study was undertaken from data collected from postmenopausal and premenopausal women of similar height and weight of general population of Hubli city. After a detailed medical history on the basis of the following inclusion and exclusion criteria 50 postmenopausal women and 50 premenopausal women were taken. We used convenience type of sampling. It is a non-probability sampling design. Postmenopausal state was considered in women who had at least 12 months amenorrhea.

\section{Inclusion Criteria}

Fifty post-menopausal women aged 50-55 years with active physical life and attained menopause naturally. Weight -60 to 65 kgs. Height $-155-157.5$ cms., were measured. Normal healthy aged 35 to 40 years with height and weight matched fifty premenopausal women with regular menstrual cycles were taken.

\section{Exclusion Criteria}

Participants with these diseases were excluded. Diseases like dyslipidaemia blood disorders, surgical menopause, hypertension, Diabetes Mellitus, thyroid disorders, renal diseases, they should not have received oestrogen therapy or supportive treatment for menopausal symptoms.

Statistical analysis is done by student ' $t$ ' test. 


\begin{tabular}{|c|c|c|c|c|c|}
\hline Parameter & $\begin{array}{c}\text { Postmenopausal Group } \\
\text { (Mean } \pm \text { SD) }\end{array}$ & $\begin{array}{c}\text { Premenopausal Group } \\
\text { (Mean } \pm \text { SD) }\end{array}$ & t Value & p Value & Significance \\
\hline Pulse (beats/min) & $82.16 \pm 2.13$ & $80.76 \pm 2.0$ & 3.37 & $<0.01$ & $\mathrm{HS}$ \\
\hline Systolic Blood Pressure (mmHg) & $121 \pm 2.75$ & $119 \pm 3.10$ & 3.68 & $<0.0001$ & $\mathrm{HS}$ \\
\hline Diastolic Blood Pressure (mmHg) & $81.76 \pm 2.16$ & $80.28 \pm 4.04$ & 2.28 & $<0.05$ & $\mathrm{~S}$ \\
\hline \multicolumn{2}{|r|}{ Table 1. Vital Data of Study of Postmenopausal Group and Premenopausal Group } \\
\hline
\end{tabular}

They were advised to follow their routine daily diet and working routine.

\section{Anthropometric Data}

Subjects were relaxed standing erect with their arms at their sides and feet together. Height and weight measurement were recorded.

Wall mounted stadiometer was used to record body height.

Clinical weighing machine was used to record weight for subjects dressed in light clothes and no shoes.

BMI was calculated as per formula: Weight $(\mathrm{Kg}) /$ Height (meter) ${ }^{2}$ (Quetelet, s Index).

Vital parameters like pulse rate, BP were recorded. Mercury Sphygmomanometer was used to measure Blood pressure.

The BP of the subjects were measured in supine position or sitting position first by palpatory method and then by auscultatory method. Accordingly, Korotkoff sounds, appearance of sound (Phase I) is taken as Systolic BP, and disappearance of (phase V) Korotkoff sound is taken as Diastolic BP.

\section{Methods of Collection of Data}

Women population of Hubli city was randomly selected with similar height and weight matched both pre and postmenopausal women were taken for study. Proforma was given to all of them. Written consents are taken during the face to face questionnaire interview. An examination of respiratory, cardiovascular, central nervous system and gynaecological examination was done.

\section{RESULTS}

\section{Vital Data}

The vital data of the healthy postmenopausal women and the healthy premenopausal is shown in table.

\section{Resting Pulse Rate}

The [mean \pm SD] pulse rate at rest in postmenopausal group groups was $82.16 \pm 2.13$ beats/ min and in premenopausal group $80.76 \pm 2.0$ beats $/ \mathrm{min}$. Higher statistical difference is seen in the resting pulse rate between the two different groups

\section{Blood Pressure}

The [mean $\pm \mathrm{SD}$ ] systolic blood pressure in postmenopausal group was $121.0 \pm 2.75 \mathrm{~mm} \mathrm{Hg}$ and in premenopausal $119 \pm$ $3.10 \mathrm{~mm}$ Hg. The [mean $\pm \mathrm{SD}$ ] diastolic blood pressure in postmenopausal group was $81.76 \pm 2.16 \mathrm{~mm} \mathrm{Hg}$ and in premenopausal $80.28 \pm 4.04 \mathrm{~mm} \mathrm{Hg}$. Higher statistical difference in the blood pressure is observed in both systolic and diastolic phases between the two different groups. There was a higher in Pulse rate (bpm) $(82.16 \pm 2.31)$, Systolic Blood Pressure $(\mathrm{mmHg})(121 \pm 2.75)$, Diastolic Blood Pressure (mmHg) $(81.76 \pm 2.16)$, in postmenopausal women.

\section{DISCUSSION}

Due to ageing there is rise in systolic blood pressure caused by a higher in vascular stiffness of the great arteries in combination with atherosclerotic changes in the vessel wall, A.H.E.M. mass (2009). ${ }^{4}$ During menopausal transition blood pressure raises due to additive effect of other hormone related factors. Decrease in oestrogen levels around menopause causes an up regulation of the RAS with an higher in plasma-renin activity. Sympathetic activity is higher in postmenopausal women than in age-matched men, especially in women who are overweight. Sympathetic over activity is associated with abdominal visceral fat which is strongly related to higher inflammatory markers and oxidative stress.

Giuseppe, et al (2006) ${ }^{1}$ says premenopausal women have low blood pressure than in age-matched men arterial blood pressure higher after the cessation of menses and that after the menopause women develop arterial hypertension often together with changes in lipid and glucose metabolism.

Many studies convey that production of catecholamines is raised and a clear shift of the autonomic control towards a higher sympathetic activity of the cardiovascular system. This higher sympathetic drive is closely related to the state of oestrogen deficiency as it occurs in a few days after surgical oophorectomy and is reversed by oestrogens. Metabolic changes with raised sympathetic drive occurring after the menopause, contribute to cause the metabolic syndrome. The physiological and structural changes, due to higher sympathetic drive leads to hypertension development.

Chow, et al (1997), 5 says after menopause both systolic and diastolic blood pressures are higher than in men of the same age, suggesting that age-related higher in blood pressure may be due to oestrogen deficiency.

European study Poehlam ET, et al (1997), ${ }^{6}$ found after menopause SBP markedly higher. De Meersmen RE, et al (1998), ${ }^{7}$ say that administration of oestrogen after menopause either attenuated the higher of both systolic and diastolic blood pressures or had no detectable effect. Peters HW, et al (1999), ${ }^{8}$ Akahoshi M, et al (1996), ${ }^{9}$ Poehlam ET, et al (1997),6 showed menopause had no effect on DBP. But Shelley, et al(1998) ${ }^{10}$ showed in a longitudinal study during menopausal transition DBP higher as BMI higher. Diastolic blood pressure may thus be a unique value to evaluate individual risk of CHD.

\section{CONCLUSIONS}

Both systolic blood pressure and diastolic blood pressure showed markedly higher in postmenopausal women. The decline in oestrogen levels around menopause causes an up regulation of the RAS with a plasma renin activity. Sympathetic over activity is associated with abdominal visceral fat which is strongly related to higher inflammatory markers and oxidative stress

In postmenopausal women both systolic and DBP, pulse rate is remarkably higher. Similar results were observed in Giuseppe et al 2006 studies. These differences may be due to 
higher of oestrogen levels around menopause that causes an up regulation of RAS with a raise in plasma renin activity.

\section{REFERENCES}

[1] Fini M. Hypertension in postmenopause women. European Endocrine Disease 2006:1-6.

[2] Vaishali S, Sanjeev S, Neelima S, et al. Status of antioxidant enzymes and trace metals in postmenopausal women. J ObstetGynecol India2005;55(1):64-6.

[3] Igweh JC, Nwagha IU, Okaro JM.The effects of menopause on the serum lipid profile of normal females of south east Nigeria. Nigerian Journal of Physiological Sciences 2005;20(1-2):48-53.

[4] Maas AH, Franke HR. Women's health in menopause with a focus on hypertension. Neth Heart Journal 2009;17(2):68-72.

[5] Chow SN, Huang CC, Lee YT. Demographic characteristics and medical aspects of menopausal women in Taiwan. J Formos Med Assoc 1997;96(10):806-11.

[6] Poehlman ET, Toth MJ, Ades PA, et alaEur J Clin Invest 1997;27(4):322-6.

[7] De Meersman RE, Zion AS, GiardinaEG, et al.Estrogen replacement, vascular distensibility and blood pressure in postmenopausal women. Am J Physiol 1998;274(5):H1539-44.

[8] Peters HW, Westendorp IC, Hak AE, et al. Menopausal status and risk factors for cardiovascular disease. J Intern Med 1999;246(6):521-8.

[9] Akahoshi M, Soda M, Nakashima E, et al. Effects of menopause on trends of serum cholesterol, blood pressure and body mass index. Circulation 1996;94(1):61-6.

[10] Shelley JM, Green A, Smith AM, et al. Relationship of endogenous sex hormones to lipids and blood pressure in mid-aged women. Ann Epidemiol 1998;8(1):39-45. 